\title{
Novel perfused compression bioreactor system as an in vitro model to investigate fracture healing
}

\author{
Waldemar Hoffmann ${ }^{1,2,3}$, Sandra Feliciano ${ }^{1,2}$, Ivan Martin ${ }^{1,2}{ }^{*}$, Michael de Wild $^{3}$ and David Wendt ${ }^{1,2}$ \\ ${ }^{1}$ Department of Biomedicine, University Hospital Basel, Basel, Switzerland \\ ${ }^{2}$ Department of Surgery, University Hospital Basel, Basel, Switzerland \\ ${ }^{3}$ School of Life Sciences, Institute for Medical and Analytical Technologies, University of Applied Sciences Northwestern Switzerland, Muttenz, Switzerland
}

Edited by:

Jöns Gunnar Hilborn, Uppsala

University, Sweden

\section{Reviewed by:}

Enrico Lucarelli, Isituto Ortopedico

Rizzoli, Italy

Vivek Mudera, University College

London, UK

Michael Raghunath, National

University of SIngapore, Singapore

*Correspondence:

Ivan Martin, Institute for Surgical Research and Hospital Management University Hospital Basel,

Hebelstrasse 20, 4031 Basel,

Switzerland

e-mail: ivan.martin@usb.ch
Secondary bone fracture healing is a physiological process that leads to functional tissue regeneration via endochondral bone formation. In vivo studies have demonstrated that early mobilization and the application of mechanical loads enhances the process of fracture healing. However, the influence of specific mechanical stimuli and particular effects during specific phases of fracture healing remain to be elucidated. In this work, we have developed and provided proof-of-concept of an in vitro human organotypic model of physiological loading of a cartilage callus, based on a novel perfused compression bioreactor (PCB) system. We then used the fracture callus model to investigate the regulatory role of dynamic mechanical loading. Our findings provide a proof-of-principle that dynamic mechanical loading applied by the PCB can enhance the maturation process of mesenchymal stromal cells toward late hypertrophic chondrocytes and the mineralization of the deposited extracellular matrix. The PCB provides a promising tool to study fracture healing and for the in vitro assessment of alternative fracture treatments based on engineered tissue grafts or pharmaceutical compounds, allowing for the reduction of animal experiments.

Keywords: bioreactor, in vitro model, mechanical loading, hypertrophy, fracture healing

\section{INTRODUCTION}

Bone fracture healing is a natural, physiological process leading to functional tissue regeneration through a highly orchestrated sequence (Gerstenfeld et al., 2003; Behonick et al., 2007; Marsell and Einhorn, 2011). Primary fracture healing occurs within stable fracture sites when there is direct contact between the fracture ends, re-establishing the anatomically correct and biomechanically competent lamellar bone structure (Marsell and Einhorn, 2011). However, in the majority of cases a gap is present at the fracture site, and therefore indirect or secondary fracture healing occurs.

Secondary fracture healing, a process recapitulating the process of endochondral bone formation, is divided into four main phases: hemorrhage and inflammation, soft callus formation, hard callus formation, and callus remodeling (Sfeir et al., 2005; Schindeler et al., 2008). Following initial hemorrhage and inflammation, a key step during secondary fracture healing is the formation of a soft fracture callus, consisting of cartilaginous extracellular matrix, chondrocytes, and fibroblasts. It provides mechanical support to the fracture and serves as a template for subsequent remodeling into a bony callus (Gerstenfeld et al., 2003; Sfeir et al., 2005; Schindeler et al., 2008). During the subsequent phase of hard callus formation, a mineralized cartilaginous template is gradually replaced with unordered woven bone matrix. The callus becomes vascularized, increasing the oxygen tension, and fostering maturation of osteoblasts (Sfeir et al., 2005; Schindeler et al., 2008). In the final phase, the woven bone is fully remodeled toward cortical and/or trabecular bone in a spatially and temporally choreographed manner (Sfeir et al., 2005; Schindeler et al., 2008).
In vivo models have demonstrated that mechanical stimulation of fractures can improve the secondary fracture healing process and/or alter the biological pathways involved (Rand et al., 1981; Goodship and Kenwright, 1985; Aro et al., 1991; Claes et al., 1997; Park et al., 1998; Rubin et al., 2001; Chao and Inoue, 2003). However, due to the multitude of parameters that play a role in the mechanical environment of the fracture site, these in vivo studies did not allow for a systematic study of specific mechanical stimuli nor their influence during the different phases of fracture healing (Gerstenfeld et al., 2003; Schindeler et al., 2008).

As an alternative, in vitro model systems facilitate a methodical approach to study the impact of the mechanical stimuli during distinct phases of secondary fracture healing in a controlled manner. However, in vitro models have previously been limited to applying mechanical loads on cartilaginous tissues in order to develop more functional tissues or to study the impact of different loading regimes on chondrogenesis (Démarteau et al., 2003; Ballyns and Bonassar, 2010; Sun et al., 2010; Puetzer et al., 2012), but the effect of mechanical loading during the process of hypertrophic cartilage formation and remodeling, critical in fracture healing, has not yet been studied.

Here, were propose an in vitro model based on a perfused compression bioreactor (PCB) system to: (i) apply physiological strain/loads, (ii) perfuse a construct allowing for mass transport and simulation of vascularization, and (iii) compress rigid load-bearing scaffolds in a physiological manner. The application of dynamic mechanical loading was validated for both collagen-based and nickel-titanium (NiTi) based tissue constructs, highlighting the broad operational range of 
the system including the compressive strength (100-200 MPa) of bone (Keaveny et al., 2004; Weiner and Wagner, 1998). In a proof-of-concept study, we hypothesized that physiological compressive loading applied during hypertrophy enhances extracellular matrix mineralization of cartilaginous constructs and triggers the maturation process of MSC toward late hypertrophic chondrocytes.

\section{MATERIALS AND METHODS PERFUSED COMPRESSION BIOREACTOR SYSTEM}

The PCB system consists of two main components: the bioreactor chamber (Figures 1A,B) and the power transmission rack (Figure 1C). A detailed description of the bioreactor system can be found in Hoffmann et al. (2014b). The bioreactor chamber holds the scaffold in place and ensures hermetic sealing as well as force transmission onto the cell loaded construct. It consists of medium inlets/outlets, flow distributors, a flexible force transmitting disk, and the intended space for scaffold/construct placement. The power transmission rack includes a plunger, a pre-load screw, and a cam-shaft. The chamber is placed on the plunger and fixed via tightening of the pre-load screw. The cam-shaft moves the plunger in order to apply a sinusoidal compression pattern onto the bioreactor chamber.

To minimize the potential for contamination, all electronics and mechanical instrumentation were housed beneath the bioreactor chambers in a closed environment. The overall dimensions were kept sufficiently small (width $\times$ height $\times$ depth: $9 \mathrm{~cm} \times$ $25 \mathrm{~cm} \times 35 \mathrm{~cm}$ ) to fit in a standard $\mathrm{CO}_{2}$ incubator (Figure 1C).

The system is controlled and monitored using a custom-made program based on LabView (NI, 622X, Austin, TX, USA) installed on a dedicated PC. This software controls the motor connected to the cam-shaft (Figure 1D) via a belt-drive generating a sinusoidal waveform for compression and simultaneously monitors data from four independent force sensors (Figure 1D, FC23 Compression Load Cell ${ }^{\circledR}$, Measurement Specialties, VA, USA).

\section{CELl CULTURE}

Human mesenchymal stromal cells (MSC) were isolated from bone marrow aspirates (Braccini et al., 2005), after informed patient consent and following protocol approval by the local ethical committee (University Hospital Basel; Prof. Dr. Kummer; approval date 26/03/2007 Ref Number 78/07), and cultured as previously described (Frank et al., 2002). MSC were expanded for two to four passages for subsequent experiments. Then MSC were seeded on type I collagen-based OPTIMAIX scaffolds (O3D304030 Matricel, Germany, punched to cylindrical shape, $3 \mathrm{~mm}$ height, $8 \mathrm{~mm}$ diameter) or NiTi scaffolds ( $4 \mathrm{~mm}$ height, $8 \mathrm{~mm}$ diameter, open-porous 3D-printed structure) (Hoffmann et al., 2014a) with a seeding density of $4 \mathrm{E}+06$ cells/scaffold using a previously developed perfusion bioreactor system (Wendt et al., 2003, 2006). During the seeding phase, bidirectional perfusion was performed using syringe pumps at a perfusion velocity of $3 \mathrm{~mL} / \mathrm{min}$.

Open-porous, metallic NiTi scaffolds were included for the initial validation to ensure the broad operational range of the PCB. Further investigations were conducted using OPTIMAIX due to ease of histological assessments.

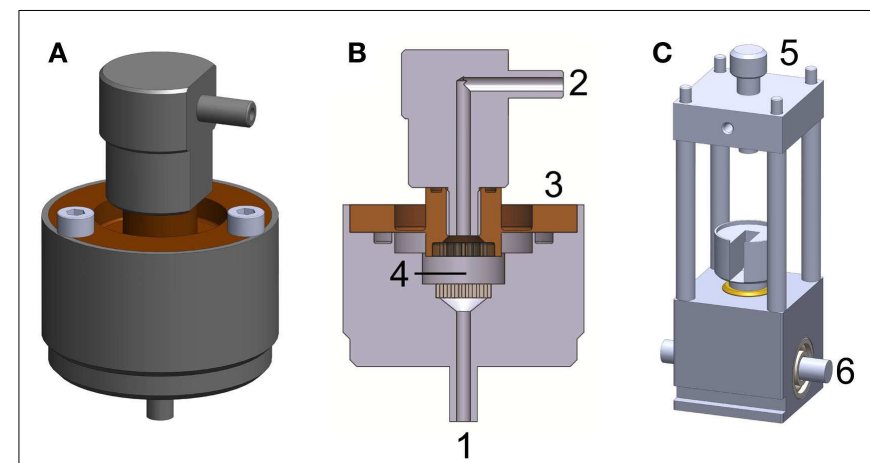

D

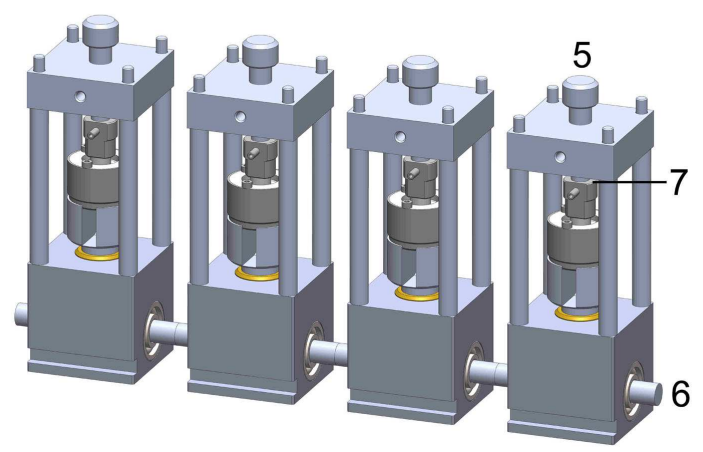

FIGURE 1 | Perfused compression bioreactor (PCB). (A) Bioreactor chamber holding the scaffold in place and ensuring hermetic sealing as well as force transmission toward the cell loaded construct. (B) Cross section of bioreactor chamber indicating medium inlets/outlets (1 and 2), flexible force transmitting disk (3), and intended space for scaffold/construct placement (4). (C) Power transmission rack including cam-shaft (6), which moves the plunger in order to apply a sinusoidal compression pattern onto the bioreactor chamber. The chamber is held in place with a pre-load screw (5) allowing for defined loading regimes. (D) A complete PCB system comprises four bioreactor chambers, four force transmission devices, and four force sensors (placed at position 7, not shown).

\section{CHONDROGENIC CONSTRUCT CULTURE}

Mesenchymal stromal cell seeded constructs were cultured for 3 weeks in chondrogenic medium (serum free medium supplemented with $0.1 \mathrm{mM}$ ascorbic acid 2-phosphate, $10 \mathrm{ng} / \mathrm{mL}$ TGF- $\beta 3$ and $10^{-7} \mathrm{M}$ dexamethasone) (Mackay et al., 1998; Barbero et al., 2003). The serum free medium consists of: Dulbecco's modified Eagle's medium (DMEM) supplemented with $1 \mathrm{mM}$ sodium pyruvate, $100 \mathrm{mM}$ HEPES buffer, $100 \mathrm{U} / \mathrm{mL}$ penicillin, $100 \mu \mathrm{g} / \mathrm{mL}$ streptomycin, $0.29 \mathrm{mg} / \mathrm{mL}$ L-glutamine, ITS $(10 \mu \mathrm{g} / \mathrm{mL}$ insulin, $5.5 \mu \mathrm{g} / \mathrm{mL}$ transferrin, $5 \mathrm{ng} / \mathrm{mL}$ selenium), $0.5 \mathrm{mg} / \mathrm{mL}$ bovine serum albumin, and $4.7 \mu \mathrm{g} / \mathrm{mL}$ linoleic acid. Using peristaltic pumps, unidirectional perfusion was applied to constructs with a perfusion velocity of $0.3 \mathrm{~mL} / \mathrm{min}$, with media changes twice per week (Santoro et al., 2011).

\section{HYPERTROPHIC CONSTRUCT CULTURE}

In order to withstand dynamic mechanical loading, stable cartilaginous templates are a prerequisite. Therefore, only constructs exhibiting good chondrogenesis were included for further investigations. Following 3 weeks of culture, cartilaginous constructs were then separated in two groups: loaded and non-loaded. 
Non-loaded specimens were maintained in the unidirectional perfusion bioreactor whereas loaded specimens were transferred to the PCB system. Hypertrophic differentiation was induced by culturing constructs for 2 weeks in serum free medium supplemented with $50 \mathrm{nM}$ thyroxine, $10 \mathrm{mM} \beta$-glycerophosphate, $10^{-8} \mathrm{M}$ dexamethasone, and $0.1 \mathrm{mM} \mathrm{L-ascorbic} \mathrm{acid-2-phosphate} \mathrm{(Scotti}$ et al., 2010). Loaded constructs were exposed to an intermittent loading regime (construct displacement $\Delta z=100 \mu \mathrm{m}$, frequency of $f=1 \mathrm{~Hz}$, three load cycles per day comprising $2 \mathrm{~h}$ of loading and $6 \mathrm{~h}$ of rest) for 2 weeks with a pre-load ensuring press fit of the construct. During the application of mechanical load, the applied forces were monitored for each bioreactor chamber separately.

\section{QUANTIFICATION OF GLYCOSAMINOGLYCAN AND DNA CONTENTS}

Chondrogenic constructs were digested in proteinase $\mathrm{K}(1 \mathrm{mg} / \mathrm{mL}$ proteinase $\mathrm{K}$ in $50 \mathrm{mM}$ Tris with $1 \mathrm{mM}$ EDTA, $1 \mathrm{mM}$ iodoacetamide, and $10 \mathrm{mg} / \mathrm{mL}$ pepstatin A) at $56^{\circ} \mathrm{C}$ overnight. The glycosaminoglycan (GAG) content of the cartilaginous constructs was determined spectrophotometrically using dimethylmethylene blue, with chondroitin sulfate as standard (Farndale et al., 1986). The DNA content of the constructs was measured using the CyQuant cell proliferation assay kit (Molecular Probes, Eugene, OR, USA) and used to normalize the GAG content.

\section{REAL-TIME RT-PCR OUANTITATION OF TRANSCRIPT LEVELS}

Total RNA was extracted from cells using Trizol ${ }^{\circledR}$ (LuBioScience $\mathrm{GmbH}$, Lucerne, Switzerland) and reverse-transcribed as previously described (Frank et al., 2002). The samples were analyzed using a GeneAmp ${ }^{\circledR}$ PCR System 9600 (Perkin Elmer, www.perkinelmer.com) and the transcription levels of the following genes of interest were quantified: collagen type-I, collagen type-II, aggrecan, cartilage oligomeric matrix protein (COMP), SOX9, and glyceraldehyde 3-phosphate dehydrogenase (GAPDH) as housekeeping gene (Barbero et al., 2003).

\section{HISTOLOGY AND IMMUNOHISTOCHEMISTRY}

After in vitro cultures, the constructs were fixed in 1.5\% paraformaldehyde and embedded in paraffin. Sections $(5-10 \mu \mathrm{m}$ thick) were stained for Safranin-O (Fluka) and Alizarin red after rehydration. Immunohistochemical analyses were performed to characterize the extracellular matrix using the following antibodies: collagen type-II (Col II; MPBiomedicals), collagen type-X (Col X; AbCam), and bone sialoprotein (BSP, 1:2000, A4232.1/A 4232.2, Immundiagnostik AG, Germany). Upon rehydration in ethanol series, sections were treated as previously described for antigen retrieval for Col II and Col X (Dickhut et al., 2009). The immunobinding was detected with biotinylated secondary antibodies and the appropriate Vectastain ABC kits. The red signal was developed with the Vector ${ }^{\circledR}$ Red kit (Linaris AK-5000) and sections counterstained by Hematoxylin. Negative controls were performed during each analysis by omitting the primary antibodies. Histological and immunohistochemical sections were analyzed using an Olympus BX-63 microscope.

\section{RESULTS}

\section{PERFUSED COMPRESSION BIOREACTOR SYSTEM}

The custom-made PCB system (Figure 1) underwent a systematic validation of the cyclic compression regime and the monitoring of the force sensors over a period of 5 weeks. Figure 2 depicts representative force diagrams for chondrogenic constructs cultured under mechanical loading for 2 weeks. Figure 2A displays a force diagram of the daily loading regime consisting of loading $(2 \mathrm{~h})$ and resting phases $(6 \mathrm{~h})$. The force necessary to compress the chondrogenic constructs remained relatively constant throughout the entire culture period (Figure 2A). During the loading phase (Figures 2B,C), a sinusoidal waveform can be seen with a periodicity of approximately $1 \mathrm{~s}$ leading to the targeted frequency of $1 \mathrm{~Hz}$. Moreover, the PCB showed a broad operational range as both collagen-based constructs (maximal force applied $110 \mathrm{~N}$, Figure 2B) and NiTi-based constructs (maximal force applied $900 \mathrm{~N}$, Figure 2C) could be stimulated without further modifications of the system.

\section{CHONDROGENIC DIFFERENTIATION}

After 3 weeks of chondrogenic culture, MSC cultured on OPTIMAIX scaffolds could generate cartilaginous tissues. Cells were embedded in lacunae and deposited extracellular matrix positively stained for GAG and collagen type II (Figure 3A). GAG contents
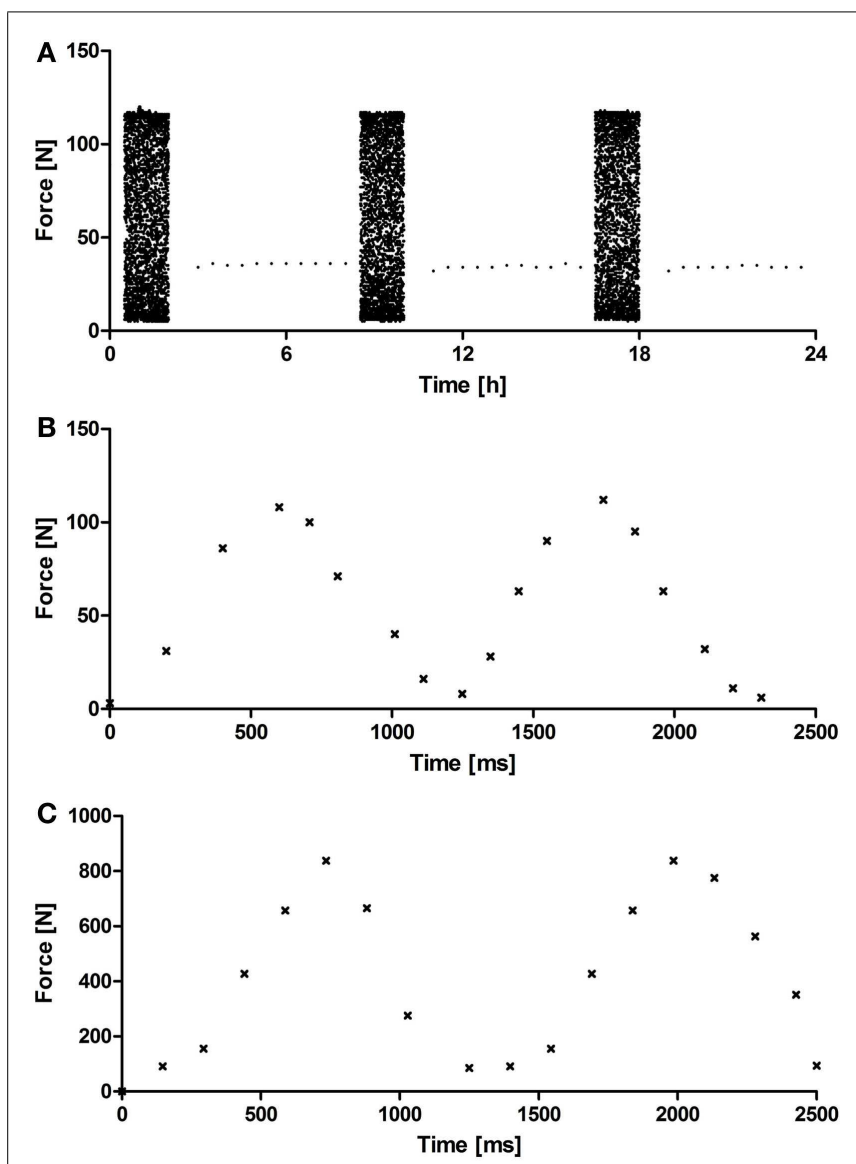

FIGURE 2 | Representative acquisition diagram from a force sensor (A) Representative force diagram acquired during $24 \mathrm{~h}$ of mechanical loading showing loading $(2 \mathrm{~h})$ and resting phases $(4 \mathrm{~h})$ for OPTIMAIX-based constructs $(n=4)$. Representative force diagram acquired during $2.5 \mathrm{~s}$ of loading showing the frequency $(1 \mathrm{~Hz})$ and periodicity of the sinusoidal wave for (B) OPTIMAIX- and (C) NiTi-based constructs $(n=4)$. 


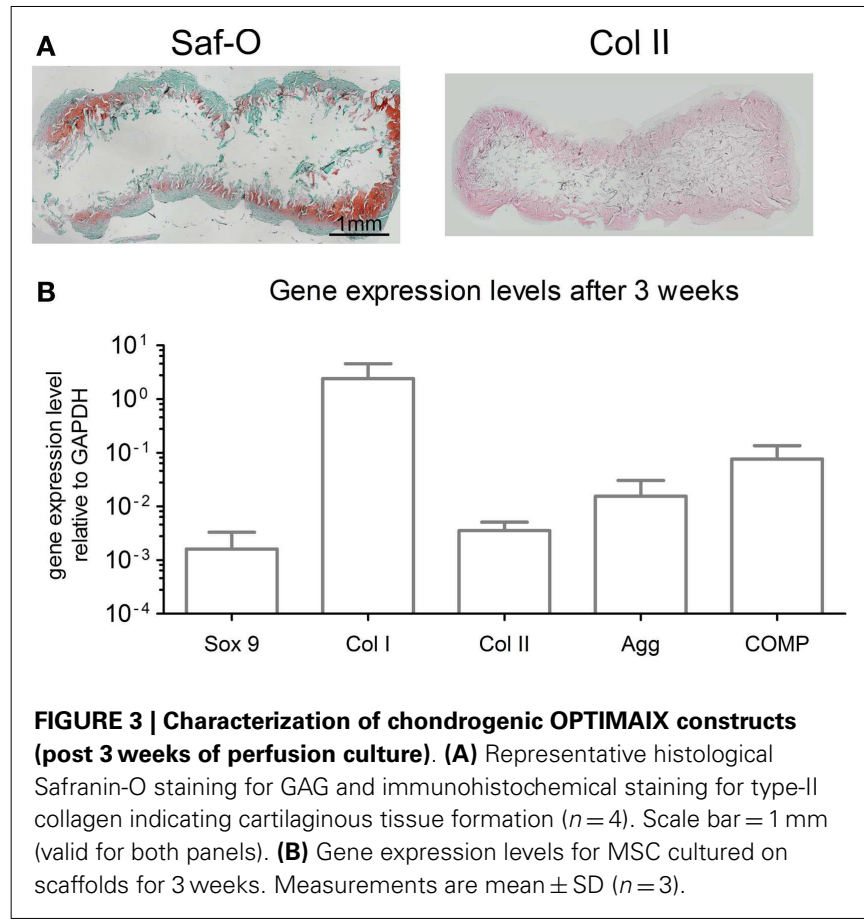

were determined to be $14.6 \pm 3.4 \mu \mathrm{g} / \mu \mathrm{g}$ (GAG/DNA). Figure 3B shows the expression levels of genes associated with chondrogenic differentiation.

\section{HYPERTROPHIC DIFFERENTIATION}

Following 2 weeks of hypertrophic differentiation, constructs exhibited increased GAG deposition (Figure 4). Similar to chondrogenic constructs, the scaffold cores of non-loaded hypertrophic constructs were devoid of GAG, yet containing fibrotic tissue and limited amounts of cells. Loaded constructs exhibited a more homogeneous distribution of GAG, but less intense staining than non-loaded constructs indicating ongoing remodeling. Collagen type-II staining of non-loaded hypertrophically differentiated constructs was increased as compared to chondrogenic constructs and loaded hypertrophic constructs.

Alizarin red staining showed that the ECM of both loaded and non-loaded constructs was mineralized preferentially along the scaffold periphery. However, loaded constructs exhibited thicker mineralized borders as compared to non-loaded constructs as well as mineralized islets within the construct. Collagen type-X staining was also observed to be preferentially deposited at the scaffold periphery in both loaded and non-loaded constructs. However, it was enriched throughout the construct in loaded samples, especially in the highly mineralized regions. BSP immunohistochemical staining indicated relatively few positively stained cells in the periphery of the non-loaded scaffolds. Loaded constructs showed high amounts of BSP-positive cells in both the peripheral regions of the constructs and within the internal central region.

\section{DISCUSSION}

In this work, we have developed a PCB system to apply physiological dynamic mechanical loads and strains on engineered

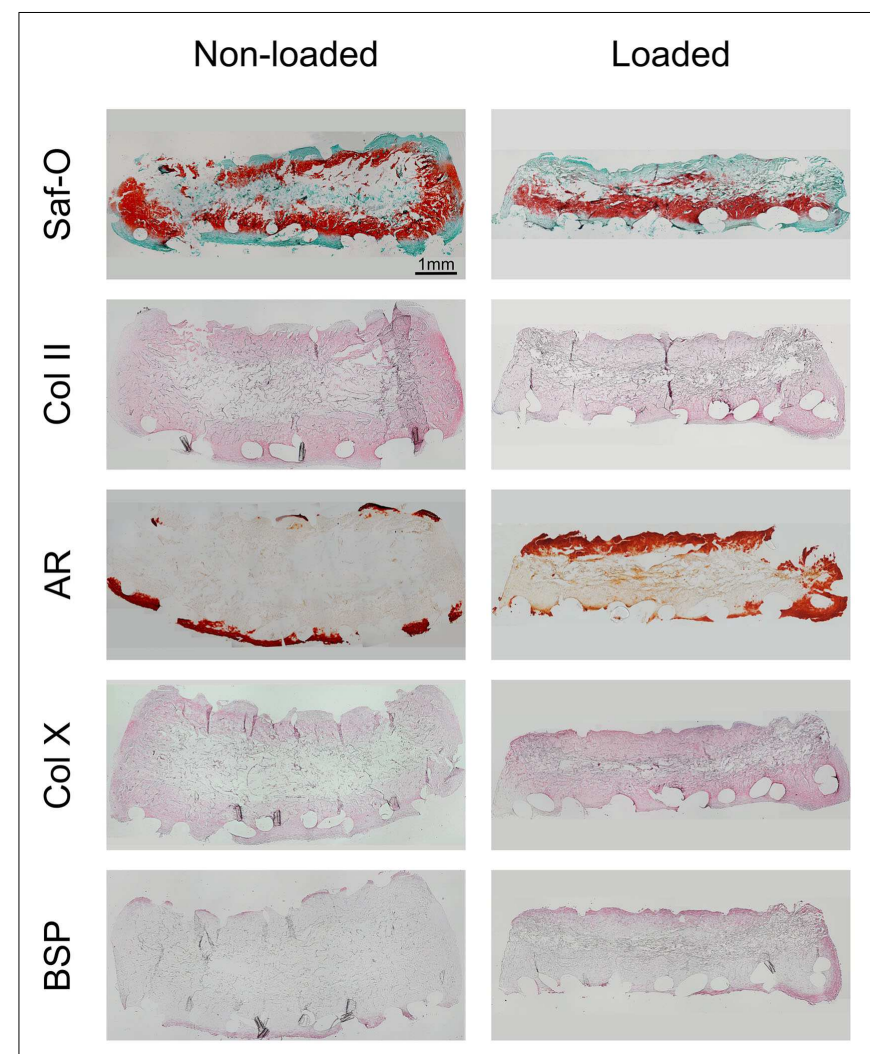

FIGURE 4 | Characterization of loaded and non-loaded constructs following the hypertrophic culture phase. The panels depict histological Safranin-O staining, immunohistochemical staining for collagen type-II, alizarin red (AR) staining and immunohistochemical staining for collagen type- $\mathrm{X}$, and bone sialoprotein (BSP), respectively $(n=4)$. Loaded constructs show a higher degree of maturation as compared to non-loaded constructs. Scale bar $=1 \mathrm{~mm}$ (valid for all panels).

constructs to investigate the process of fracture healing. A proof-of-concept study was performed applying dynamic mechanical loads onto cell seeded collagen- and NiTi-based constructs, presenting the broad operational range of the developed system.

The PCB underwent systematic validation revealing safe and reliable functionality to ensure defined dynamic mechanical loading of viable engineered tissues. As compared to previously described systems (Rath et al., 2008; Ballyns and Bonassar, 2010; Sittichokechaiwut et al., 2010; Sun et al., 2010; Lujan et al., 2011; Matziolis et al., 2011; Omata et al., 2012; Petri et al., 2012; Puetzer et al., 2012; Shahin and Doran, 2012), the PCB exhibits a broader operational range. It allows for physiological mechanical compression in a consistent and reliable manner in a range from approximately $10 \mathrm{~N}$ up to $1 \mathrm{kN}$, while maintaining compact dimensions.

Given the fact that the compression applied is displacement driven, a various range of scaffolds and tissues can be easily investigated with dynamic mechanical loading without further adaptation of the system. Additionally, this range can be further enlarged via exchanging the eccentric cam-shaft, thereby adapting the displacement toward the desired range. 
Our proof-of-concept study was conducted to assess the effect of physiological compressive loads during hypertrophic differentiation as an in vitro model for the transition from a soft to a hard callus. Since the development of a soft cartilaginous callus is a crucial step during secondary fracture healing (Schindeler et al., 2008), during the initial phase of the study, MSC were seeded on OPTIMAIX scaffolds and primed toward chondrogenesis. The resulting engineered constructs showed cartilaginous characteristics including: (i) ECM containing GAGs and collagen type-II, (ii) cells embedded in lacunae, and (iii) chondrocytic gene expression. Moreover, the cartilaginous constructs exhibited stable size and shape, enabling the application of dynamic loading within the PCB.

In our experimental setup, constructs undergoing mechanical loading during hypertrophy exhibited a higher degree of maturation than unloaded constructs. MSC embedded in the cartilaginous extracellular matrix of mechanically loaded constructs displayed enlarged lacunae to a higher extent than in non-loaded constructs. Furthermore, the diminished GAG and collagen typeII staining, as well as the high degree of mineral deposition (Mackie et al., 2008), collagen type-X content (Mackie et al., 2008; Gawlitta et al., 2010), and BSP staining (Sommer et al., 1996; Gawlitta et al., 2010) within loaded constructs underlines the late hypertrophic state of the MSC. Moreover, as BSP has been shown to be the main nucleator of hydroxyapatite crystals and to correlate with the initial phase of matrix mineralization (Bianco et al., 1993), the increased BSP staining in the ECM of mechanically loaded constructs indicates a higher degree of maturation as compared to non-loaded constructs. While this proof-of-concept study provides evidence of loading mediated hypertrophic differentiation, subsequent work should be aimed at further understanding the extent of hypertrophy (e.g., gene expression profiles).

In this study, we present our mechanically loaded hypertrophic constructs as an in vitro model of a fracture callus, which is undergoing the transition from soft to hard callus through remodeling and ossification of the soft cartilaginous callus (Gerstenfeld et al., 2003). The results obtained from our in vitro model system, i.e., application of dynamic mechanical compression during the hypertrophic differentiation phase, are consistent with previous in vivo models (Grundnes and Reikerås, 1991; Buckwalter and Grodzinsky, 1999; Hardy, 2004), which demonstrated that early mobilization and application of mechanical loads enhances the process of fracture healing. These results thus support the use of the $\mathrm{PCB}$ as an in vitro model for dynamic mechanical loading.

\section{CONCLUSION}

In this study, we have demonstrated that the developed PCB system depicts a versatile tool for the in vitro application of dynamic physiological mechanical loads onto scaffolding materials with a wide range of mechanical properties. Mechanical loading applied via the developed bioreactor system enhances ECM mineralization during hypertrophy of cartilaginous constructs and triggers the maturation process of MSC toward late hypertrophic chondrocytes as demonstrated through the decrease in GAG and collagen type-II, the thickened mineralized border, the increased amounts of type-X collagen and positive BSP staining. Furthermore, the application of cyclic mechanical loading leads to the maturation of scaffold-based constructs. In combination with the fracture callus model, the PCB displays an advanced in vitro model and a promising tool for further studies testing alternative fracture treatments, based on engineered grafts or pharmaceutical compounds. Additionally, toward implementation of the 3R principles (replace, reduce, and refine) (Goldberg et al., 1996), this system could lead to a reduction of animal experiments within the field.

\section{ACKNOWLEDGMENTS}

The authors thank Atanas Todorov for his technical support. Furthermore, we gratefully acknowledge the financial funding of the Swiss National Science Foundation within the research program NRP 62 “Smart Materials” (Grant No. 406240_126123).

\section{SUPPLEMENTARY MATERIAL}

The Supplementary Material for this article can be found online at http://www.frontiersin.org/Journal/10.3389/fbioe.2015.00010/ abstract

\section{REFERENCES}

Aro, H. T., Wahner, H. T., and Chao, E. Y. (1991). Healing patterns of transverse and oblique osteotomies in the canine tibia under external fixation. J. Orthop. Trauma 5, 351-364. doi:10.1097/00005131-199109000-00016

Ballyns, J. J., and Bonassar, L. J. (2010). Dynamic compressive loading of imageguided tissue engineered meniscal constructs. J. Biomech. 44, 509-516. doi:10. 1016/j.jbiomech.2010.09.017

Barbero, A., Ploegert, S., Heberer, M., and Martin, I. (2003). Plasticity of clonal populations of dedifferentiated adult human articular chondrocytes. Arthritis Rheum. 48, 1315-1325. doi:10.1002/art.10950

Behonick, D. J., Xing, Z., Lieu, S., Buckley, J. M., Lotz, J. C., Marcucio, R. S., et al. (2007). Role of matrix metalloproteinase 13 in both endochondral and intramembranous ossification during skeletal regeneration. PLoS ONE 2:e1150. doi:10.1371/journal.pone.0001150

Bianco, P., Riminucci, M., Silvestrini, G., Bonucci, E., Termine, J. D., Fisher, L. W., et al. (1993). Localization of bone sialoprotein (BSP) to Golgi and post-Golgi secretory structures in osteoblasts and to discrete sites in early bone matrix. J. Histochem. Cytochem. 41, 193-203. doi:10.1177/41.2.8419459

Braccini, A., Wendt, D., Jaquiery, C., Jakob, M., Heberer, M., Kenins, L., et al. (2005). Three-dimensional perfusion culture of human bone marrow cells and generation of osteoinductive grafts. Stem Cells 23, 1066-1072. doi:10.1634/stemcells. 2005-0002

Buckwalter, J. A., and Grodzinsky, A. J. (1999). Loading of healing bone, fibrous tissue, and muscle: implications for orthopaedic practice. J. Am. Acad. Orthop. Surg. 7, 291-299.

Chao, E. Y. S., and Inoue, N. (2003). Biophysical stimulation of bone fracture repair, regeneration and remodelling. Eur. Cell. Mater. 6, 72-84; discussion 84-5.

Claes, L., Augat, P., Suger, G., and Wilke, H. J. (1997). Influence of size and stability of the osteotomy gap on the success of fracture healing. J. Orthop. Res. 15, 577-584. doi:10.1002/jor.1100150414

Démarteau, O., Jakob, M., Schäfer, D., Heberer, M., and Martin, I. (2003). Development and validation of a bioreactor for physical stimulation of engineered cartilage. Biorheology 40, 331-336.

Dickhut, A., Pelttari, K., Janicki, P., Wagner, W., Eckstein, V., Egermann, M., et al. (2009). Calcification or dedifferentiation: requirement to lock mesenchymal stem cells in a desired differentiation stage. J. Cell. Physiol. 219, 219-226. doi: $10.1002 /$ jcp. 21673

Farndale, R. W., Buttle, D. J., and Barrett, A. J. (1986). Improved quantitation and discrimination of sulphated glycosaminoglycans by use of dimethylmethylene blue. Biochim. Biophys. Acta 883, 173-177. doi:10.1016/0304-4165(86)90306-5

Frank, O., Heim, M., Jakob, M., Barbero, A., Schäfer, D., Bendik, I., et al. (2002). Real-time quantitative RT-PCR analysis of human bone marrow stromal cells during osteogenic differentiation in vitro. J. Cell. Biochem. 85, 737-746. doi:10. 1002/jcb. 10174

Gawlitta, D., Farrell, E., Malda, J., Creemers, L. B., Alblas, J., and Dhert, W. J. A. (2010). Modulating endochondral ossification of multipotent stromal cells for 
bone regeneration. Tissue Eng. Part B. Rev. 16, 385-395. doi:10.1089/ten.TEB. 2009.0712

Gerstenfeld, L. C., Cullinane, D. M., Barnes, G. L., Graves, D. T., and Einhorn, T. A. (2003). Fracture healing as a post-natal developmental process: molecular, spatial, and temporal aspects of its regulation. J. Cell. Biochem. 88, 873-884. doi:10.1002/jcb.10435

Goldberg, A. M., Zurlo, J., and Rudacille, D. (1996). The three Rs and biomedical research. Sci. 272, 1403. doi:10.1126/science.272.5267.1403

Goodship, A. E., and Kenwright, J. (1985). The influence of induced micromovement upon the healing of experimental tibial fractures. J. Bone Joint Surg. Br. 67, 650-655.

Grundnes, O., and Reikerås, O. (1991). Mechanical effects of function on bone healing. Nonweight bearing and exercise in osteotomized rats. Acta Orthop. Scand. 62, 163-165. doi:10.3109/17453679108999248

Hardy, M. A. (2004). Principles of metacarpal and phalangeal fracture management: a review of rehabilitation concepts. J. Orthop. Sports Phys. Ther. 34, 781-799. doi:10.2519/jospt.2004.34.12.781

Hoffmann, W., Bormann, T., Rossi, A., Muller, B., Schumacher, R., Martin, I., et al. (2014a). Rapid prototyped porous nickel-titanium scaffolds as bone substitutes. J. Tissue Eng. 5, doi:10.1177/2041731414540674

Hoffmann, W., Döbeli, C., Santoro, R., Wendt, D., and de Wild, M. (2014b). Reactor Device for Mechanical Loading of Tissue Specimens and/or Engineered Tissues. European Patent Office Munich, priority application, EP 14/169756.

Keaveny, T. M., Morgan, E. F., Yeh, O. C., Material, C., Bone, C., and Bone, T. (2004). "Bone mechanics," in Standard handbook of Biomedical Engineering and Design $1-24$.

Lujan, T. J., Wirtz, K. M., Bahney, C. S., Madey, S. M., Johnstone, B., and Bottlang, M. (2011). A novel bioreactor for the dynamic stimulation and mechanical evaluation of multiple tissue-engineered constructs. Tissue Eng. Part C Methods 17, 367-374. doi:10.1089/ten.tec.2010.0381

Mackay, A. M., Beck, S. C., Murphy, J. M., Barry, F. P., Chichester, C. O., and Pittenger, M. F. (1998). Chondrogenic differentiation of cultured human mesenchymal stem cells from marrow. Tissue Eng. 4, 415-428. doi:10.1089/ten. 1998.4.415

Mackie, E. J., Ahmed, Y. A., Tatarczuch, L., Chen, K.-S., and Mirams, M. (2008). Endochondral ossification: how cartilage is converted into bone in the developing skeleton. Int. J. Biochem. Cell Biol. 40, 46-62. doi:10.1016/j.biocel. 2007.06.009

Marsell, R., and Einhorn, T. A. (2011). The biology of fracture healing. Injury 42, 551-555. doi:10.1016/j.injury.2011.03.031

Matziolis, D., Tuischer, J., Matziolis, G., Kasper, G., Duda, G., and Perka, C. (2011). Osteogenic predifferentiation of human bone marrow-derived stem cells by short-term mechanical stimulation. Open Orthop. J. 5, 1-6. doi:10.2174/ 1874325001105010001

Omata, S., Sonokawa, S., Sawae, Y., and Murakami, T. (2012). Effects of both vitamin $\mathrm{C}$ and mechanical stimulation on improving the mechanical characteristics of regenerated cartilage. Biochem. Biophys. Res. Commun. 424, 724-729. doi:10.1016/j.bbrc.2012.07.019

Park, S. H., O'Connor, K., McKellop, H., and Sarmiento, A. (1998). The influence of active shear or compressive motion on fracture-healing. J. Bone Joint Surg. Am. 80, 868-878.

Petri, M., Ufer, K., Toma, I., Becher, C., Liodakis, E., Brand, S., et al. (2012) Effects of perfusion and cyclic compression on in vitro tissue engineered meniscus implants. Knee Surg. Sports Traumatol. Arthrosc. 20, 223-231. doi:10.1007/ s00167-011-1600-3

Puetzer, J. L., Ballyns, J. J., and Bonassar, L. J. (2012). The effect of the duration of mechanical stimulation and post-stimulation culture on the structure and properties of dynamically compressed tissue-engineered menisci. Tissue Eng. Part A 18, 1365-1375. doi:10.1089/ten.TEA.2011.0589

Rand, J. A., An, K. N., Chao, E. Y., and Kelly, P. J. (1981). A comparison of the effect of open intramedullary nailing and compression-plate fixation on fracture-site blood flow and fracture union. J. Bone Joint Surg. Am. 63, 427-442.
Rath, B., Nam, J., Knobloch, T. J., Lannutti, J. J., and Agarwal, S. (2008). Compressive forces induce osteogenic gene expression in calvarial osteoblasts. J. Biomech. 41, 1095-1103. doi:10.1016/j.jbiomech.2007.11.024

Rubin, C., Bolander, M., Ryaby, J. P., and Hadjiargyrou, M. (2001). The use of lowintensity ultrasound to accelerate the healing of fractures. J. Bone Joint Surg. Am. 83-A, 259-270.

Santoro, R., Krause, C., Martin, I., and Wendt, D. (2011). On-line monitoring of oxygen as a non-destructive method to quantify cells in engineered $3 \mathrm{D}$ tissue constructs. J. Tissue Eng. Regen. Med. 6, 696-701. doi:10.1002/term.473

Schindeler, A., McDonald, M. M., Bokko, P., and Little, D. G. (2008). Bone remodeling during fracture repair: the cellular picture. Semin. Cell Dev. Biol. 19, 459-466. doi:10.1016/j.semcdb.2008.07.004

Scotti, C., Tonnarelli, B., Papadimitropoulos, A., Scherberich, A., Schaeren, S. Schauerte, A., et al. (2010). Recapitulation of endochondral bone formation using human adult mesenchymal stem cells as a paradigm for developmental engineering. Proc. Natl. Acad. Sci. U. S. A. 107, 7251-7256. doi:10.1073/pnas. 1000302107

Sfeir, C., Ho, L., Doll, B. A., Azari, K., and Hollinger, J. O. (2005). “Fracture repair," in Bone Regeneration and Repair: Biology and Clinical Applications, eds J. R. Lieberman and G. E. Friedlaender (New York: Humana Press Inc.), 21-44.

Shahin, K., and Doran, P. M. (2012). Tissue engineering of cartilage using a mechanobioreactor exerting simultaneous mechanical shear and compression to simulate the rolling action of articular joints. Biotechnol. Bioeng. 109, 1060-1073. doi:10.1002/bit.24372

Sittichokechaiwut, A., Edwards, J. H., Scutt, A. M., and Reilly, G. C. (2010). Short bouts of mechanical loading are as effective as dexamethasone at inducing matrix production by human bone marrow mesenchymal stem cell. Eur. Cell. Mater. 20, 45-57.

Sommer, B., Bickel, M., Hofstetter, W., and Wetterwald, A. (1996). Expression of matrix proteins during the development of mineralized tissues. Bone 19, 371-380. doi:10.1016/S8756-3282(96)00218-9

Sun, M., Lv, D., Zhang, C., and Zhu, L. (2010). Culturing functional cartilage tissue under a novel bionic mechanical condition. Med. Hypotheses 75, 657-659. doi:10.1016/j.mehy.2010.08.011

Weiner, S., and Wagner, H. D. (1998). THE MATERIAL BONE: structure-mechanical function relations. Annu. Rev. Mater. Sci. 28, 271-298. doi:10.1146/annurev. matsci.28.1.271

Wendt, D., Marsano, A., Jakob, M., Heberer, M., and Martin, I. (2003). Oscillating perfusion of cell suspensions through three-dimensional scaffolds enhances cell seeding efficiency and uniformity. Biotechnol. Bioeng. 84, 205-214. doi:10.1002/ bit.10759

Wendt, D., Stroebel, S., Jakob, M., John, G. T., and Martin, I. (2006). Uniform tissues engineered by seeding and culturing cells in $3 \mathrm{D}$ scaffolds under perfusion at defined oxygen tensions. Biorheology 43, 481-488.

Conflict of Interest Statement: The authors declare that the research was conducted in the absence of any commercial or financial relationships that could be construed as a potential conflict of interest.

Received: 17 November 2014; paper pending published: 28 November 2014; accepted: 16 January 2015; published online: 02 February 2015.

Citation: Hoffmann W, Feliciano S, Martin I, de Wild M and Wendt D (2015) Novel perfused compression bioreactor system as an in vitro model to investigate fracture healing. Front. Bioeng. Biotechnol. 3:10. doi: 10.3389/fbioe.2015.00010

This article was submitted to Tissue Engineering and Regenerative Medicine, a section of the journal Frontiers in Bioengineering and Biotechnology.

Copyright (c) 2015 Hoffmann, Feliciano, Martin, de Wild and Wendt. This is an openaccess article distributed under the terms of the Creative Commons Attribution License (CC BY). The use, distribution or reproduction in other forums is permitted, provided the original author(s) or licensor are credited and that the original publication in this journal is cited, in accordance with accepted academic practice. No use, distribution or reproduction is permitted which does not comply with these terms. 